\title{
Cervical Arthroplasty
}

\section{William T. Couldwell, MD}

Editor-in-Chief, Neurosurgical Focus

It is a pleasure of mine to introduce the January 2017 Video Supplement, containing superb informational surgical videos on the topic of cervical arthroplasty. This nicely complements the upcoming monthly issue of Neurosurgical Focus on the same topic.

This supplement is important for two reasons: it addresses an emerging standard of practice for cervical spine surgeons, and also introduces a new phase in the expansion of online features of Neurosurgical Focus. As of this New Year, we have increased the frequency of video supplements to appear quarterly. The topics of the video issues will be much more diverse, covering the breadth of operative neurosurgery. This will encompass both macro- and microsurgical video, and cover such diverse clinical arenas such as spine, functional, skull base, and open and endovascular surgery. Our wish is that these video supplements will enhance the educational materials offered by Focus and enable surgeons around the world to learn from subspecialty leaders of our field. 